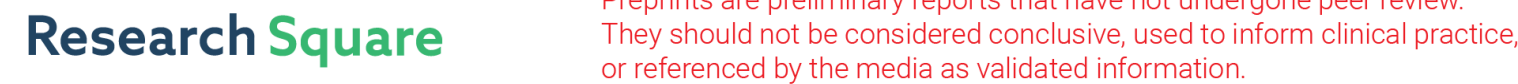

\section{Plasma vanin-1 as a novel biomarker of sepsis for trauma patients: a prospective multicenter cohort study}

\section{Hongxiang Lu}

General Hospital of Xinjiang Military Region

Anqiang Zhang

Army Medicial University

Dalin Wen

Army Medical Unioversity

Juan Du

Army Medical University

Jianhui Sun

Army Medicial University

Liang Qiao

Army Medical University

Dingyuan Du

Chongqing University

Wei Gu ( $\square$ clgwjm@163.com )

Chongqing University https://orcid.org/0000-0002-9529-4683

Jianxin Jiang

Army Medical University

Research

Keywords: Vanin-1, Biomarker, Trauma, Sepsis

Posted Date: December 28th, 2020

DOI: https://doi.org/10.21203/rs.3.rs-133544/v1

License: (c) (i) This work is licensed under a Creative Commons Attribution 4.0 International License. Read Full License 


\section{Abstract}

\section{Backgroud}

Vanin-1 plays a pivotal role in oxidative stress and the inflammatory response. However, its relationship with traumatic sepsis remains unknown. The aim of our study was to evaluate whether plasma vanin-1 expression can be used to predict traumatic sepsis in an early time.

Methods

In this three-stage prospective cohort study, severe trauma patients admitted to two hospitals from January 2015 to October 2018 were enrolled. Clinical data during hospitalization and APACHE II score were collected. Plasma vanin-1 levels were measured by enzyme linked immunosorbent assay. The associations among variables and traumatic sepsis were identified by logistic regression model. The receiveroperating characteristic curve was analyzed to evaluate the diagnostic efficiency of the selected factors.

Results

A total of 426 trauma patients (22 patients in the discovery cohort, 283 patients in the internal test cohort, and 121 patients in the external validation cohort) and 16 healthy volunteers were enrolled. The plasma vanin- 1 level of trauma patients was significantly higher than that of healthy volunteers $(P<0.05)$, and sepsis patients had higher plasma vanin- 1 than non-sepsis patients in the discovery trauma cohort $(P<0.05)$. In the internal test cohort, plasma vanin-1 levels at day 1 after trauma were significantly associated with the incidence of sepsis (OR $=3.92,95 \%$ $\left.\mathrm{Cl}=2.68-5.72, P=1.62 \subseteq 10^{-12}\right)$. As a predictive biomarker, vanin-1 obtained a better area under the curve (AUC) $(0.82,95 \% \mathrm{Cl}=0.77-0.87)$ than C-reaction protein (CRP) $(0.62,95 \% \mathrm{Cl}=0.56-0.68, P<0.0001)$, procalciton in $(\mathrm{PCT})(0.66,95 \% \mathrm{Cl}=0.60-0.71, P<0.0001)$, and Acute Physiology and Chronic Health Evaluation II (APACHE II) $\left(0.71,95 \% \mathrm{Cl}=0.65-0.76, P=6.70 \subseteq 10^{-3}\right)$. In addition, the clinical relevance between plasma vanin-1 and traumatic sepsis was validated in the external validation cohort $\left(\mathrm{OR}=4.26,95 \% \mathrm{Cl}=2.22-8.17, P=1.28 \subseteq 10^{-5}\right)$. The AUC of vanin-1 was $0.83(95 \% \mathrm{Cl}=0.75-0.89)$, which was better than that of CRP, PCT, and APACHE II.

Conclusions

Our study demonstrated that plasma vanin-1 increased among trauma patients and was independently associated with the risk of sepsis. Vanin-1 might be a potential biomarker for the early prediction of traumatic sepsis.

Trial registration

Clinicaltrials.gov Identifier NCT01713205. Registered 24 October 2012.

\section{Background}

Sepsis is one of the most common complications and the leading cause of in-hospital death for severe trauma patients $(1,2)$. Sepsis results in a longer length of hospital stay and higher health care costs, which greatly increases the burden on society $(3,4)$. However, the diagnosis of post-traumatic sepsis is notoriously difficult in the sense that trauma patients are in a state of "sterile inflammation"(5). The strong oxidative stress induced by severe injury may produce a genomic storm with an alteration of up to $80 \%$ of the leukocyte transcriptome which largely affecting the parameters used to diagnose sepsis(6).Considering the consequences of sepsis after trauma, early recognition and individualized therapy of those patients at high risk of sepsis are essential prerequisites to reduce the morbidity of trauma patients $(7,8)$. Therefore, finding an ideal biomarker facilitating the early prediction of post-injury sepsis is highly warranted.

Vanin-1 (Vascular non-inflammatory molecule 1, VNN1) is a pantetheinase that hydrolyzes pantetheine to pantothenic acid (vitamin B5) and cysteamine. Beyond its function in coenzyme A (COA) metabolism, VNN1 has been found to participate in both oxidative stress and the inflammatory response $(9,10)$. $V N N 1^{-/-}$mice showed increased tolerance to oxidative stress caused by $\gamma$-irradiation or paraquat in toxication (11). In addition, they showed an attenuated inflammatory reaction after infection by schistosomiasis (12) or rickettsiosis (13). In patients with multiple injuries, physical damage is the initiating factor in the production of oxygen free radicals and inflammatory reactions, and numerous studies have demonstrated associations between injury and elevated oxidative stress and inflammation (14). Therefore, we hypothesized that vanin-1 might increase in response to physiological stress in trauma patients and might act as a potential predictive biomarker of traumatic sepsis.

In this multicenter study, we detected the change of plasmavanin-1 levels in trauma patients. Then, we investigated the relationship between vanin-1 expression and incidence of sepsis. In addition, a prospective cohort study was conducted to evaluate the predictive power of plasma vanin-1 for traumatic sepsis. Finally, an independent cohort was conducted to validate these findings. Our aim is to determine whether plasma vanin-1 could act as a potential biomarker for the early diagnosis of sepsis in trauma patients. 


\section{Methods}

\section{Study design and setting}

The present study was a two-center, prospective cohort investigation. Severe trauma patients with an Injury Severity Score (ISS) greater than 16 points, admitted to the hospital within 24 hours after injury were enrolled from the ICU at the Department of Trauma Surgery from Daping Hospital and the Centre Hospital of Chongqing University during January 2015 to October 2018. Patients who met one of the following criteria were excluded: 1) age < 15 years old or > 65 years old; 2) pregnancy; 3 ) malignant tumor; 4) serious chronic history of cardiovascular, respiratory, renal, hepatic, hematologic, or immunological diseases. Sixteen healthy volunteers were asymptomatic nonsmokers under 65 years of age, who had no known chronic medical conditions.

This study includes a discovery cohort and two test cohorts. Patients were followed up during the hospital stay and divided into sepsis and nonsepsis group during data analysis according to the occurrence of sepsis, which was defined as a suspected infection with an acute change in SOFA scores $\geq 2$ (Sepsis-3) (15). The definition of infection was a clinically obvious source or positive bacterial culture.

The research was approved by the Institutional Ethics Review Board of the Army Medical University. Informed consent of all patients was obtained from the patients or their relatives. The National Clinical Trial number is NCT01713205. Registered 24 October 2012.

\section{Data Collection}

Demographic characteristics and clinical data, including general condition, vital signs and consciousness state were retrieved from the electronic medical records. Acute Physiology and Chronic Health Evaluation (APACHE) II scores and Sequential Organ Failure Assessment (SOFA) scores were calculated to evaluate the disease severity and organ failures.

\section{Detection of Vanin-1 in Plasma}

Blood specimens were collected and processed as previously reported (2). Briefly, whole blood was collected using an EDTA-coated tube immediately after admission and kept at $4^{\circ} \mathrm{C}$. Sample was centrifuged within 1 hour at $3000 \mathrm{rpm}$ for 5 minutes at $4^{\circ} \mathrm{C}$. The plasma was separated and stored at $-80^{\circ} \mathrm{Cfor}$ further analyses. To test the dynamic change in plasma vanin- 1 , blood samples at days $1,3,5,7$, and 14 after injury were collected in the discovery cohort. The basic levels of plasma vanin-1 were measured among 16 healthy volunteers. A commercially available enzyme-linked immunosorbent assay (ELISA) (Cloud-Clone Corp, USA) was conducted to detect vanin-1 in plasma.Vanin-1 levels were determined in duplicate following the manufacturer's instructions.

\section{Statistical analysis}

Categorical variables were summarized as number and proportion, and the differences were compared with the $\chi 2$ test. Continuous variables were expressed as the median and inter quartile ranges (IQRs, 25-75th percentiles), and comparisons were performed using Mann-Whitney $U$ test. The associations among variables and traumatic sepsis were identified by logistic regression model. Additionally, we made adjustment with age, sex and ISS to correct the associations. The evaluation of the predictive accuracy was performed using the area under the curve (AUC) of the receiver operating characteristic (ROC) curve. The correlations between vanin-1 and other variables were assessed using Spearman rank correlation coefficient. The statistically significant differences were $P<0.05$. All statistical analyses were performed using SPSS version 17.0 (SPSS Inc., Chicago, USA) and MedCalc version 13 (MedCalc Software, Ostend, Belgium).

\section{Results}

\section{The Clinical data and General Information}

In total, 426 patients suffering from severe injury were enrolled in our study, including 305 patients (11 sepsis patients and 11 non-sepsis patients were randomly selected as the discovery cohort, and the remaining 283 patients as the internal test cohort), and 121 patients from Chongqing Emergency Medical Center as the external validation cohort. The age, gender, injuries and infections among three groups were comparable (Table 1). Most patients developed sepsis 3-5 days after injury. Gram-negative bacteria were the main pathogenic microorganisms, while pneumonia and primary bloodstream infections were the major infection sites.

\section{Table 1. Clinical characteristics of trauma patients}




\begin{tabular}{|c|c|c|c|c|}
\hline Variables & $\begin{array}{l}\text { Discovery } \\
\text { cohort } \\
(n=22)\end{array}$ & $\begin{array}{l}\text { Internal test } \\
\text { cohort } \\
(n=283)\end{array}$ & $\begin{array}{l}\text { External validation cohort } \\
(n=121)\end{array}$ & $P$ value* \\
\hline Gender囚Female/Male『 & $4 / 18$ & $59 / 224$ & $28 / 93$ & 0.90 \\
\hline Age (years) & $44.75 \pm 15.02$ & $43.39 \pm 12.01$ & $44.48 \pm 12.65$ & 0.68 \\
\hline ISS & $26.85 \pm 9.19$ & $24.45 \pm 8.44$ & $22.97 \pm 8.56$ & 0.10 \\
\hline $\mathrm{AIS}_{\text {Head/neck }}$ & $2.55 \pm 1.76$ & $1.80 \pm 1.67$ & $1.80 \pm 1.65$ & 0.10 \\
\hline $\mathrm{AIS}_{\text {Face }}$ & $0.40 \pm 0.60$ & $0.43 \pm 0.79$ & $0.28 \pm 0.59$ & 0.12 \\
\hline $\mathrm{AlS}_{\text {Thorax }}$ & $3.05 \pm 1.23$ & $2.71 \pm 1.26$ & $3.01 \pm 1.06$ & 0.43 \\
\hline $\mathrm{AIS}_{\text {Abdomen }}$ & $1.65 \pm 1.66$ & $1.26 \pm 1.52$ & $1.30 \pm 1.32$ & 0.47 \\
\hline AIS $_{\text {Upper/lower extremity }}$ & $1.70 \pm 1.13$ & $2.17 \pm 1.49$ & $1.95 \pm 1.63$ & 0.07 \\
\hline GCS initial & $13.85 \pm 6.16$ & $14.00 \pm 3.00$ & $13.78 \pm 2.68$ & 0.32 \\
\hline APACHE II scores initial & $7.85 \pm 3.76$ & $7.67 \pm 6.31$ & $7.40 \pm 4.57$ & 0.92 \\
\hline SOFA scores initial & $1.85 \pm 1.18$ & $2.95 \pm 2.22$ & $2.28 \pm 1.41$ & 0.10 \\
\hline Sepsis, n (\%) & - & $91(32.16 \%)$ & $41(33.88 \%)$ & 0.73 \\
\hline Pathogens, n (\%) & & & & 0.46 \\
\hline Gram-negative & - & $62(68.13 \%)$ & $21(51.22 \%)$ & \\
\hline Gram-positive & - & $11(12.09 \%)$ & $8(19.51 \%)$ & \\
\hline Mixed gram-negative and -positive & - & $7(7.69 \%)$ & $5(12.20 \%)$ & \\
\hline Others & - & $4(4.40 \%)$ & $2(4.87 \%)$ & \\
\hline Negative blood cultures & - & $7(7.69 \%)$ & $\mathbf{5}(12.20 \%)$ & \\
\hline Source of infection, n (\%) & & & & 0.41 \\
\hline Blood & - & $25(27.47 \%)$ & $10(24.39 \%)$ & \\
\hline Sputum & - & $27(29.68 \%)$ & $13(31.71 \%)$ & \\
\hline Urine & - & $15(16.48 \%)$ & $8(19.51 \%)$ & \\
\hline Secretions & - & $18(19.78 \%)$ & $4(9.76 \%)$ & \\
\hline Others & - & $6(6.59 \%)$ & $6(14.63 \%)$ & \\
\hline Time trauma-sepsis onset, days & $5.85 \pm 2.91$ & $5.76 \pm 4.82$ & $5.03 \pm 2.52$ & 0.72 \\
\hline ICU days & $6.16 \pm 9.22$ & $4.47 \pm 7.92$ & $5.76 \pm 13.01$ & 0.99 \\
\hline Deaths & $0(0.00 \%)$ & $9(3.18 \%)$ & $3(2.48 \%)$ & 0.66 \\
\hline
\end{tabular}

ISS, injury severity score; AIS, Abbreviated Injury Scale; GCS, Glasgow Coma Scale; APACHE II, Acute Physiology and Chronic Health Evaluation II; SOFA, sequential organ failure assessment.

*Categorical variables were compared using the $\chi 2$ test and continuous variables were compared using ANOVA test.

\section{The dynamic change of plasma vanin-1 after injury}

The median plasma vanin-1 levels were $0.63 \mathrm{ng} / \mathrm{mL}(\mathrm{IQR}, 0.52-0.66 \mathrm{ng} / \mathrm{mL})$ for healthy population. Trauma patients had the highest plasma vanin- 1 on the first day of admission $\left(1.73 \pm 1.07 \mathrm{ng} / \mathrm{ml}, P=1.21 \times 10^{-4}\right.$, discovery cohort) (Figure $\left.1 \mathrm{~A}\right)$. Then, the level of vanin-1 gradually declined from day 3 to day 14 after injury but was still significantly higher than that of healthy controls ( $P<0.01$ for all days). We further compared plasma levels of vanin-1 between the sepsis and the non-sepsis group. Significantly elevated plasma levels of vanin-1 were found in sepsis patients, especially on early days after admission ( $P=0.03$ for day 1 and $P=0.04$ for day 3 ), indicated the potential predictive value of vanin-1levels for sepsis in trauma patients (Figure 1B). No significant difference was demonstrated between two groups at day 5,7 , and 14 . 
To investigate whether plasma vanin-1 could be used as a predictive biomarker of traumatic sepsis, we evaluated the predictive power of plasma vanin-1at day 1 in 283 trauma patients (Internal test cohort). Our results showed a strong association between higher plasma vanin-1 levels taken 24 hours post injury and the incidence of secondary sepsis within the subsequent 14 days $\left(P=6.02 \times 10^{-13}\right)($ Figure $2 A)$. No significant correlation between ISS and plasma vanin-1 was observed $\left(r^{2}=0.01, P=0.06\right)$. In addition, our results demonstrated that the level of plasma vanin-1 at day 1 was significantly associated with the incidence of sepsis patients after trauma $(\mathrm{OR}=3.89,95 \% \mathrm{Cl}=2.68-5.63$, $\left.P=6.99 \times 10^{-13}\right)$ (Table S1). Logistical regression analyses also demonstrated that plasma vanin-1 was significantly related to a higher occurrence of sepsis adjusted by age, sex, smoking, drinking, and ISS (OR=3.92, 95\% $\mathrm{Cl}=2.68-5.72, P=1.67 \times 10^{-12}$, Table 2 ). Based on the ROC analysis of plasma vanin-1at day 1 , an AUC of 0.82 ( $95 \% \mathrm{Cl}=0.77-0.87$ ) was obtained for the morbidity of sepsis after trauma (Figure $3 \mathrm{~A}$ ). The optimal cut-off value was $1.41 \mathrm{ng} / \mathrm{ml}$ in the internal test cohort with the sensitivity and specificity of $70.00 \%$ and $84.90 \%$, respectively (Table S2). Although CRP, PCT, and APACHE II at day 1 after trauma were also associated with the risk of traumatic sepsis in our internal test cohort(Table S1, S2 and Table 2), our results revealed that vanin-1 had a better AUC than other biomarkers (CRP, $P<0.0001$; PCT, $P<0.0001$; APACHE II, $P=6.70 \times 10^{-3}$ ) (Figure $3 \mathrm{~A}$ ).

Table 2. Associations between each biomarker and traumatic sepsis in adjusted logistic regression models

\begin{tabular}{|c|c|c|c|c|}
\hline \multirow{2}{*}{ Variables } & \multicolumn{2}{|c|}{ Internal test cohort } & \multicolumn{2}{|c|}{ External validation cohort } \\
\hline & OR $(95 \%$ CI $)$ & $P^{*}$ & OR $(95 \%$ CI $)$ & $P^{*}$ \\
\hline APACHE II & $1.17(1.10-1.23)$ & $5.35 \times 10^{-8}$ & $1.21(1.08-1.37)$ & $1.00 \times 10^{-3}$ \\
\hline PCT & $1.06(1.02-1.10)$ & $2.00 \times 10^{-3}$ & $0.99(0.90-1.08)$ & 0.86 \\
\hline $\mathrm{CRP}$ & $1.01(1.00-1.01)$ & $3.00 \times 10^{-3}$ & $1.01(1.00-1.02)$ & 0.05 \\
\hline Vanin-1 & $3.92(2.68-5.72)$ & $1.62 \times 10^{-12}$ & $4.26(2.22-8.17)$ & $1.28 \times 10^{-5}$ \\
\hline
\end{tabular}

APACHE II, Acute Physiology and Chronic Health Evaluation II; PCT, procalcitonin; CRP, C-reactive protein.

*Adjusted by age, sex, smoking, drinking, and ISS.

\section{The Validation of Vanin-1 for Predicet Sepsis in Trauma Patients}

We further validate the predictive ability of plasma vanin-1at day 1 after injury in the external validation cohort. In this cohort, plasma vanin1 was also not associated with ISS $\left(r^{2}=0.03, P=0.07\right)$. Sepsis patients had significant higher plasma vanin- 1 than non-sepsis patients at day 1 after injury $\left(\mathrm{P}=8.39 \times 10^{-6}\right)$ (Figure $2 \mathrm{~B}$ ). Plasma vanin-1at day 1 after injury was also associated with the risk of sepsis, adjusted by age, sex, smoking, drinking, and ISS (OR=4.26, 95\% Cl=2.22-8.17, $P=1.28 \times 10^{-5}$, Table 2). Plasma vanin- 1 obtained an $\mathrm{AUC}$ of 0.83 (95\% $\left.\mathrm{Cl}=0.75-0.89\right)$ for the incidence of sepsis after trauma (Figure 3B). The optimal cut-off value was $1.35 \mathrm{ng} / \mathrm{ml}$ in the external validation cohort, with a sensitivity and specificity of $70.73 \%$ and $90.00 \%$, respectively (Additional file 1: Table S2). We also analyzed the associations between CRP, PCT, APACHE II and traumatic sepsis. Except for the PCT, the remaining CRP and APACHE II were related to the risk of sepsis after trauma (Table 2 and Additional file 1: Table S1). When compared with CRP (AUC=0.59, 95\% Cl=0.500-0.68, $\left.P=1.20 \times 10^{-3}\right), \mathrm{PCT}(\mathrm{AUC}=0.63,95 \% \mathrm{Cl}=0.54-0.71$, $P=1.30 \times 10^{-3}$ ), and APACHEII (AUC=0.72, 95\% $\mathrm{Cl}=0.63-0.80, P=0.09$ ), vanin-1 also obtained a better predictive ability (Figure 3B and Table 3 ). Furthermore, combining plasma vanin-1 with APACHE II increased the diagnostic efficiency $(\mathrm{AUC}=0.85, \mathrm{Table} 3)$.

Table 3. Predictive probability of single predictor in trauma cohort 


\begin{tabular}{|c|c|c|c|c|c|c|c|c|c|c|c|c|}
\hline \multirow[t]{2}{*}{ Variables } & \multicolumn{6}{|c|}{ Internal test cohort } & \multicolumn{6}{|c|}{ External validation cohort } \\
\hline & AUC & $\begin{array}{l}\text { Sensitivity } \\
\text { (\%) }\end{array}$ & $\begin{array}{l}\text { Specificity } \\
(\%)\end{array}$ & $\begin{array}{l}\text { PPV } \\
(\%)\end{array}$ & $\begin{array}{l}\text { NPV } \\
(\%)\end{array}$ & $\begin{array}{l}\text { Cut- } \\
\text { off }\end{array}$ & AUC & $\begin{array}{l}\text { Sensitivity } \\
\text { (\%) }\end{array}$ & $\begin{array}{l}\text { Specificity } \\
\text { (\%) }\end{array}$ & $\begin{array}{l}\text { PPV } \\
(\%)\end{array}$ & $\begin{array}{l}\text { NPV } \\
(\%)\end{array}$ & $\begin{array}{l}\text { Cut- } \\
\text { off } \\
(\%)\end{array}$ \\
\hline CRP & $\begin{array}{l}0.62(0.56- \\
0.68)\end{array}$ & 37.36 & 84.37 & 53.1 & 74.0 & 79.8 & $\begin{array}{l}0.59(0.50- \\
0.68)\end{array}$ & 78.05 & $43.75 \%$ & 41.6 & 79.5 & 3 \\
\hline РCT & $\begin{array}{l}0.66(0.60- \\
0.71)\end{array}$ & 67.03 & 59.90 & 44.2 & 79.3 & 0.67 & $\begin{array}{l}0.63(0.54- \\
0.71)\end{array}$ & 80.49 & $40.00 \%$ & 40.7 & 80.0 & 0.219 \\
\hline APACHEII & $\begin{array}{l}0.71(0.65- \\
0.76)\end{array}$ & 62.64 & 69.29 & 49.1 & 79.6 & 6 & $\begin{array}{l}0.72(0.63- \\
0.80)\end{array}$ & 78.05 & $56.25 \%$ & 47.8 & 83.3 & 6 \\
\hline Vanin-1 & $\begin{array}{l}0.82(0.77- \\
0.87)\end{array}$ & 70.33 & 84.90 & 68.8 & 85.8 & 1.41 & $\begin{array}{l}0.83(0.75- \\
0.89)\end{array}$ & 70.73 & $90.00 \%$ & 78.4 & 85.7 & 1.35 \\
\hline $\begin{array}{l}\text { APACHE } \\
\text { II }+ \\
\text { Vanin-1 }\end{array}$ & $\begin{array}{l}0.85(0.80- \\
0.89)\end{array}$ & 70.45 & 86.98 & - & - & - & $\begin{array}{l}0.87(0.80- \\
0.93)\end{array}$ & 80.49 & $87.50 \%$ & - & - & - \\
\hline
\end{tabular}

CRP, C-reactive protein; PCT, procalcitonin; APACHE II, Acute Physiology and Chronic Health Evaluation II; AUC, area under curve; PPV, positive predictive value; NPV, negative predictive value.

\section{Discussion}

Increasing evidence has highlighted the importance of vanin-1 in various cancer and inflammatory disorders, including septic shock (17). However, whether vanin-1 could be used as a biomarker for early warning of traumatic sepsis is still unknown. In this study, elevated admission plasma vanin-1 levels were observed in severe trauma patients. We have demonstrated that increased admission vanin-1 was significantly associated with the incidence of sepsis in severe trauma patients. Furthermore, after adjusted with age, sex, smoking, drinking, and ISS, vanin-1 was strongly associated with sepsis. When plasma vanin-1 was used as a biomarker for the early prediction of traumatic sepsis, better predictive abilities were obtained than PCT, CRP and APACHE II in both of our validate cohorts.

In previous studies, VNN1 mRNA had been used to predict the risk or prognosis of colorectal cancer $(18,19)$ and acute myeloid leukemia patients (20). Elevated circulation or urinary vanin-1 has been reported in acute/chronic kidney injury(21, 22), drug-induced renal injury (23) and asthma patients (24). We demonstrated in the current study that plasma vanin-1 increased rapidly after injury. Specially, patients who developed sepsis later have higher plamsa vanin-1 on admission. It is consistent with the findings from our group through reanalyzing genomewide expression of leukocytes from trauma patients in the public traumatic website (The Human Genomic Response to Severe Traumatic Injury, http://web.mgh.harvard.edu/TRT/). In this public database, VNN1 mRNA was upregulated and differentially expressed between the complicated recovery group and the uncomplicated recovery group within 12 hours and at 1, 4, 7, 14, 21, and 28 days after injury. We further analyzed the public transcriptome data of sepsis patients from the GEO dataset (https://www.ncbi.nlm.nih.gov/gds/). Upregulation of VNN1 mRNA in sepsis patients was obviously detected in the GSE28750 (25), GSE64457 (26), and GSE46995 (27).

It has been controversial that whether PCT and CRP can be used to predict the incidence of sepsis in trauma patients (28). In this study, we showed that both PCT and CRP were not suitable for diagnosing sepsis in severe trauma patients, with low sensitivity or specificity. In our two larger trauma cohorts, plasma vanin-1 at day 1 after trauma was independently associated with the incidence of traumatic sepsis even adjusted by age, sex, smoking, drinking, and ISS in the multiple logistic regression analysis. It could predict the risk of sepsis after trauma with an AUC over 0.80 . Compared with CRP, PCT, and APACHE II, plasma vanin-1 outperformed the predicted ability in our study cohorts. When vanin1 was combined with the APACHE II score, the AUC could be increased to 0.85 . All of these findings supported vanin-1 increases in trauma patients, and plasma vanin-1 might be used as a potential biomarker of post-injury sepsis at the early stage. The potential relevance of plasma vanin-1 would help clinicians categorize high-risk sepsis patients at the early stage of trauma and enable rapid treatment, improve outcomes, and reduce unnecessary antibiotic therapy.

To our knowledge, little has been known about the mechanisms of how vanin-1 influences the process of sepsis. VNN1 might play a protective role against oxidative stress and the inflammatory response caused by infection $(29,30)$. Yamashita et al. reported vanin-1 elevation in patients with influenza A (H1N1) pneumonia (31). Furthermore, VNN1 mRNA increased significantly in the human alveolar epithelial carcinoma cell line A549 in response to TNF- $a$, IL-6, IL-1 $\beta$, lipopolysaccharides (LPS) and $\mathrm{H}_{2} \mathrm{O}_{2}$. These studies indicated that the strong oxidative stress caused by injury also induced the upregulation of VNN1 mRNA. In addition, injury and subsequent pro-inflammatory cytokines, such as TNF-a and IL-1 1 , might upregulate VNN1 mRNA levels $(31,32)$. Additionally, previous studies demonstrated that glutathione, the most potent cellular antioxidant, was elevated in $\mathrm{VNN1}^{-/-}$mice, resulting in a lack of cysteamine in tissues. Therefore, $\mathrm{VNN1}^{-1-}$ mice exhibited resistance to oxidative damage 
and reduced inflammatory responses (11). Moreover, there was a negative correlation between the expression levels of $V N N 1$ and peroxisome proliferator-activated receptor-y (PPARY) (33). PPARY in monocytes plays an anti-inflammatory role by inhibiting other transcription factors, such as nuclear factor-KB and activator protein $1(34,35)$. VNN1 promotes inflammation partly by inhibiting both $P P A R Y$ expression and signal transduction $(32,33)$. Lan Ling et al. suggested that VNN1 was negatively regulated by miR-203 and affected sepsis through AKT signaling pathway. Therefore, we speculated that VNN1 played an important role in sepsis development by regulating the glutathione, cysteamine, $P P A R Y$ and AKT signaling pathways. Further functional experiments might help us to clarify the role of VNN1 in sepsis development.

Some potential limitations of the present study should be considered. First, the sample size of patients in each cohort was relatively small, which was remarkable in the discovery cohort. Additional large studies are needed to validate these findings. Second, we revealed that plasma vanin-1 levels were associated with traumatic sepsis. However, howvanin-1 affects the development of sepsis is unclear. More studies with cellular and molecular experiments are required to investigate the relevant mechanisms. Finally, although the correlations between plasma vanin-1 and traumatic sepsis were validated, whether the findings could be interpreted in other ethnic groups needs further evaluation.

\section{Conclusions}

To summarize, our study demonstrated that plasma vanin-1 on admission is independently associated with the risk of traumatic sepsis and has a good predictive capacity to predict sepsis at the early stage of trauma. To confirm these findings, further studies with larger populations and functional evaluations are warranted.

\section{Abbreviations}

APACHE II: Acute physiology and chronic health evaluation II; AUC: Area under the curve; CRP: C-reaction protein; ELISA: enzyme-linked immunosorbent assay; ISS: Injury severity score; PCT: Reciprocal; PPARy: Peroxisome proliferator-activated receptor-y; ROC: Receiver operating characteristic curve; SIRS: Systemic inflammatory response syndrome; SOFA: Sequential organ failure assessment.

\section{Declarations}

\section{Ethics approval and consent to participate}

The research was approved by the Institutional Ethics Review Board of the Army Medical University. Informed consent of all patients was obtained from the patients or their relatives.

\section{Consent for publication}

Yes.

\section{Availability of data and materials}

The datasets used and analyzed during the current study are available from the corresponding author in response to reasonable requests.

\section{Competing interests}

All authors have no competing interests to disclose.

\section{Funding}

This work is supported by Science and Technology Innovation Project for Academicians of Chongqing (cstc2019jcyj-msxmX0266 and cstc2017jcyj-yszxX0007), National Natural Science Foundation of China (81772061, 81601677), Medical Research Funding of PLA of China (17QNP005 and AWS14C003).

\section{Authors' contributions}

W. Gu, A.Q. Zhang and J.X. Jiang designed the study. H.X. Lu and A.Q. Zhang were responsible for data collection and management. D.L. Wen, J. Du, D.Y. Du and J.H. Sun were responsible for sample collection and laboratory processing. H.X. Lu and L. Qiao performed statistical analysis and drafted the manuscript. W. Gu, A.Q. Zhang and J.X. Jiang critically revised the manuscript. All authors read and approved the final manuscript.

\section{Acknowledgements}


We acknowledge Dr. Dongpo Jiang and Lianyang Zhang, Army Medical University, for the collection of blood samples and clinical information. We thank all the participants who participated in this study.

\section{References}

1. Bohmer AB, Just KS, Lefering R, Paffrath $T$, Bouillon $B$, Joppich $R$, et al. Factors influencing lengths of stay in the intensive care unit for surviving trauma patients: a retrospective analysis of 30,157 cases. Crit Care. 2014;18(4):R143.

2. Zhang AQ, Gu W, Zeng L, Zhang LY, Du DY, Zhang M, et al. Genetic variants of microRNA sequences and susceptibility to sepsis in patients with major blunt trauma. Ann Surg. 2015;261(1):189-96.

3. Lamparello AJ, Namas RA, Constantine G, McKinley TO, Elster E, Vodovotz Y, et al. A conceptual time window-based model for the early stratification of trauma patients. J Intern Med. 2019;286(1):2-15.

4. Haagsma JA, Graetz N, Bolliger I, Naghavi M, Higashi H, Mullany EC, et al. The global burden of injury: incidence, mortality, disabilityadjusted life years and time trends from the Global Burden of Disease study 2013. Inj Prev. 2016;22(1):3-18.

5. Vourc'h M, Roquilly A, Asehnoune K. Trauma-Induced Damage-Associated Molecular Patterns-Mediated Remote Organ Injury and Immunosuppression in the Acutely III Patient. Front Immunol. 2018;9:1330.

6. Xiao W, Mindrinos MN, Seok J, Cuschieri J, Cuenca AG, Gao H, et al. A genomic storm in critically injured humans. J Exp Med. 2011;208(13):2581-90.

7. Lindner HA, Balaban U, Sturm T, Weiss C, Thiel M, Schneider-Lindner V. An Algorithm for Systemic Inflammatory Response Syndrome Criteria-Based Prediction of Sepsis in a Polytrauma Cohort. Crit Care Med. 2016;44(12):2199-207.

8. Asehnoune K, Balogh Z, Citerio G, Cap A, Billiar T, Stocchetti N, et al. The research agenda for trauma critical care. Intensive Care Med. 2017;43(9):1340-51.

9. Naquet P, Pitari G, Dupre S, Galland F. Role of the Vnn1 pantetheinase in tissue tolerance to stress. Biochem Soc Trans. 2014;42(4):1094100.

10. Nitto T, Onodera K. Linkage between coenzyme a metabolism and inflammation: roles of pantetheinase. J Pharmacol Sci. 2013;123(1):1-8.

11. Berruyer C, Martin FM, Castellano R, Macone A, Malergue F, Garrido-Urbani S, et al. Vanin-1-/- mice exhibit a glutathione-mediated tissue resistance to oxidative stress. Mol Cell Biol. 2004;24(16):7214-24.

12. Martin F, Penet MF, Malergue F, Lepidi H, Dessein A, Galland F, et al. Vanin-1(-/-) mice show decreased NSAID- and Schistosoma-induced intestinal inflammation associated with higher glutathione stores. J Clin Invest. 2004;113(4):591-7.

13. Meghari S, Berruyer C, Lepidi H, Galland F, Naquet P, Mege JL. Vanin-1 controls granuloma formation and macrophage polarization in Coxiella burnetii infection. Eur J Immunol. 2007;37(1):24-32.

14. Sandesc M, Rogobete AF, Bedreag OH, Dinu A, Papurica M, Cradigati CA, et al. Analysis of oxidative stress-related markers in critically ill polytrauma patients: An observational prospective single-center study. Bosn J Basic Med Sci. 2018;18(2):191-7.

15. Singer M, Deutschman CS, Seymour CW, Shankar-Hari M, Annane D, Bauer M, et al. The Third International Consensus Definitions for Sepsis and Septic Shock (Sepsis-3). JAMA. 2016;315(8):801-10.

16. Chung KP, Chen GY, Chuang TY, Huang YT, Chang HT, Chen YF, et al. Increased Plasma Acetylcarnitine in Sepsis Is Associated With Multiple Organ Dysfunction and Mortality: A Multicenter Cohort Study. Crit Care Med. 2019;47(2):210-8.

17. Ling L, Lu HT, Wang HF, Shen MJ, Zhang HB. MicroRNA-203 Acts as a Potent Suppressor in Septic Shock by Alleviating Lung Injury via Inhibition of VNN1. Kidney Blood Press Res. 2019;44(4):565-82.

18. Yip KT, Das PK, Suria D, Lim CR, Ng GH, Liew CC. A case-controlled validation study of a blood-based seven-gene biomarker panel for colorectal cancer in Malaysia. J Exp Clin Cancer Res. 2010;29:128.

19. Marshall KW, Mohr S, Khettabi FE, Nossova N, Chao S, Bao W, et al. A blood-based biomarker panel for stratifying current risk for colorectal cancer. Int J Cancer. 2010;126(5):1177-86.

20. Izzi V, Lakkala J, Devarajan R, Savolainen ER, Koistinen P, Heljasvaara R, et al. Vanin 1 (VNN1) levels predict poor outcome in acute myeloid leukemia. Am J Hematol. 2018;93(1):E4-E7.

21. Washino S, Hosohata K, Oshima M, Okochi T, Konishi T, Nakamura Y, et al. A Novel Biomarker for Acute Kidney Injury, Vanin-1, for Obstructive Nephropathy: A Prospective Cohort Pilot Study. Int J Mol Sci. 2019;20(4).

22. Hosohata K, Matsuoka H, Iwanaga K, Kumagai E. Urinary vanin-1 associated with chronic kidney disease in hypertensive patients: A pilot study. J Clin Hypertens (Greenwich). 2020;22(8):1458-65.

23. Hosohata K, Ando H, Fujiwara Y, Fujimura A. Vanin-1: a potential biomarker for nephrotoxicant-induced renal injury. Toxicology. 2011;290(1):82-8. 
24. Xiao C, Biagini Myers JM, Ji H, Metz K, Martin LJ, Lindsey M, et al. Vanin-1 expression and methylation discriminate pediatric asthma corticosteroid treatment response. J Allergy Clin Immunol. 2015;136(4):923-31 e3.

25. Sutherland A, Thomas M, Brandon RA, Brandon RB, Lipman J, Tang B, et al. Development and validation of a novel molecular biomarker diagnostic test for the early detection of sepsis. Crit Care. 2011;15(3):R149.

26. Demaret J, Venet F, Friggeri A, Cazalis MA, Plassais J, Jallades L, et al. Marked alterations of neutrophil functions during sepsis-induced immunosuppression. J Leukoc Biol. 2015;98(6):1081-90.

27. Shalova IN, Lim JY, Chittezhath M, Zinkernagel AS, Beasley F, Hernandez-Jimenez E, et al. Human monocytes undergo functional reprogramming during sepsis mediated by hypoxia-inducible factor-1alpha. Immunity. 2015;42(3):484-98.

28. Ciriello V, Gudipati S, Stavrou PZ, Kanakaris NK, Bellamy MC, Giannoudis PV. Biomarkers predicting sepsis in polytrauma patients: Current evidence. Injury. 2013;44(12):1680-92.

29. Berruyer C, Pouyet L, Millet V, Martin FM, LeGoffic A, Canonici A, et al. Vanin-1 licenses inflammatory mediator production by gut epithelial cells and controls colitis by antagonizing peroxisome proliferator-activated receptor gamma activity. J Exp Med. 2006;203(13):2817-27.

30. Pouyet L, Roisin-Bouffay C, Clement A, Millet V, Garcia S, Chasson L, et al. Epithelial vanin-1 controls inflammation-driven carcinogenesis in the colitis-associated colon cancer model. Inflamm Bowel Dis. 2010;16(1):96-104.

31. Yamashita N, Yashiro M, Ogawa H, Namba H, Nosaka N, Fujii Y, et al. Metabolic pathway catalyzed by Vanin-1 pantetheinase plays a suppressive role in influenza virus replication in human alveolar epithelial A549 cells. Biochem Biophys Res Commun. 2017;489(4):466-71.

32. Jansen PA, Kamsteeg M, Rodijk-Olthuis D, van Vlijmen-Willems IM, de Jongh GJ, Bergers M, et al. Expression of the vanin gene family in normal and inflamed human skin: induction by proinflammatory cytokines. J Invest Dermatol. 2009;129(9):2167-74.

33. Zhang B, Lo C, Shen L, Sood R, Jones C, Cusmano-Ozog K, et al. The role of vanin-1 and oxidative stress-related pathways in distinguishing acute and chronic pediatric ITP. Blood. 2011;117(17):4569-79.

34. Ricote M, Glass CK. PPARs and molecular mechanisms of transrepression. Biochim Biophys Acta. 2007;1771(8):926-35.

35. Szeles L, Torocsik D, Nagy L. PPARgamma in immunity and inflammation: cell types and diseases. Biochim Biophys Acta. 2007;1771(8):1014-30.

\section{Figures}
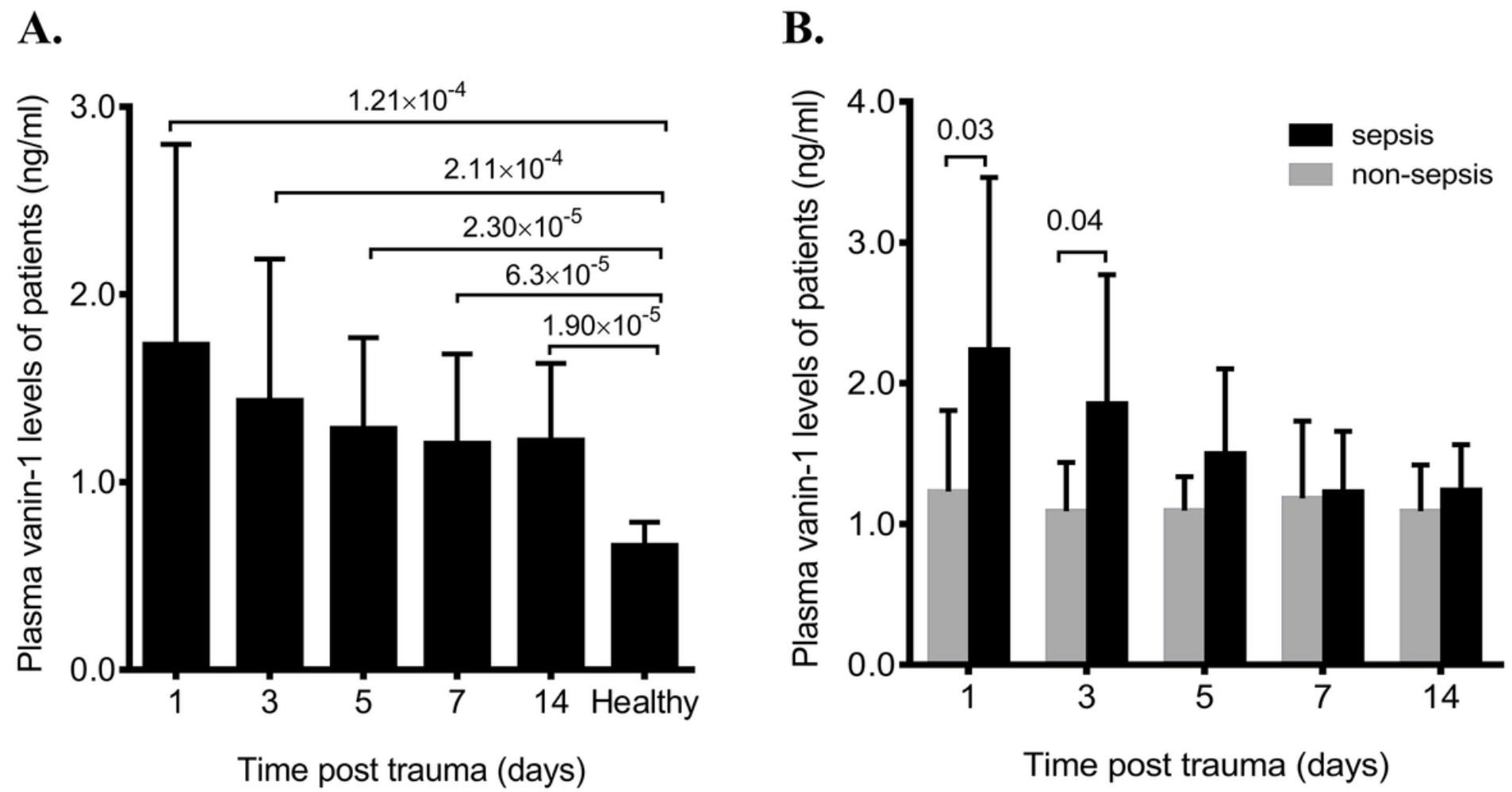

Figure 1 
Kinetics of plasma vanin-1 levels in trauma patients on admission and at days 3, 5, 7, and 14 during hospitalization from the discovery cohort. A. Plasma vanin-1 of trauma patients is significantly higher than that of healthy volunteers ( $n=22$ trauma patients vs. 16 healthy controls). B. Traumatic sepsis patients have higher plasma vanin- 1 than non-sepsis patients on the early stage after injury ( $\mathrm{n}=11$ sepsis patients vs. 11 nonsepsis patients, $\mathrm{P}=0.03$ for days 1 and $\mathrm{P}=0.04$ for days 3 ). Data are expressed as the mean and $95 \% \mathrm{Cl}$. Statistical analysis comprised Student's t test.
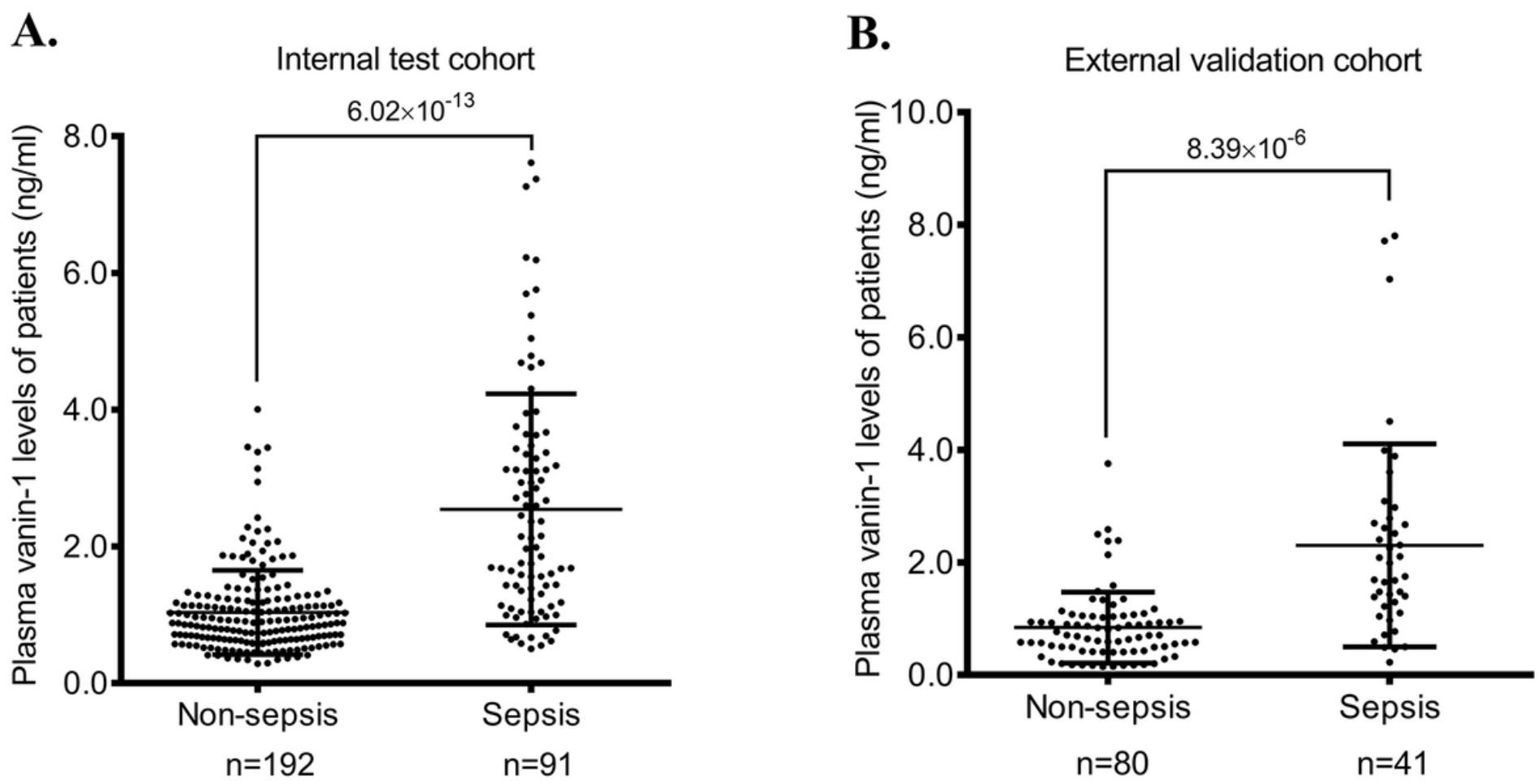

Figure 2

The plasma vanin-1 in trauma patients with and without sepsis for the internal test and external validation cohorts. Patients who developed sepsis had significantly higher levels of plasma vanin-1 when compared with patients who did not develop sepsis at day 1 after trauma (A for internal test cohort; B for external validation cohort). All samples were collected on day 1 after injury. Black bars show the mean and $95 \%$ Cl. Statistical analysis comprised Student's t test. 


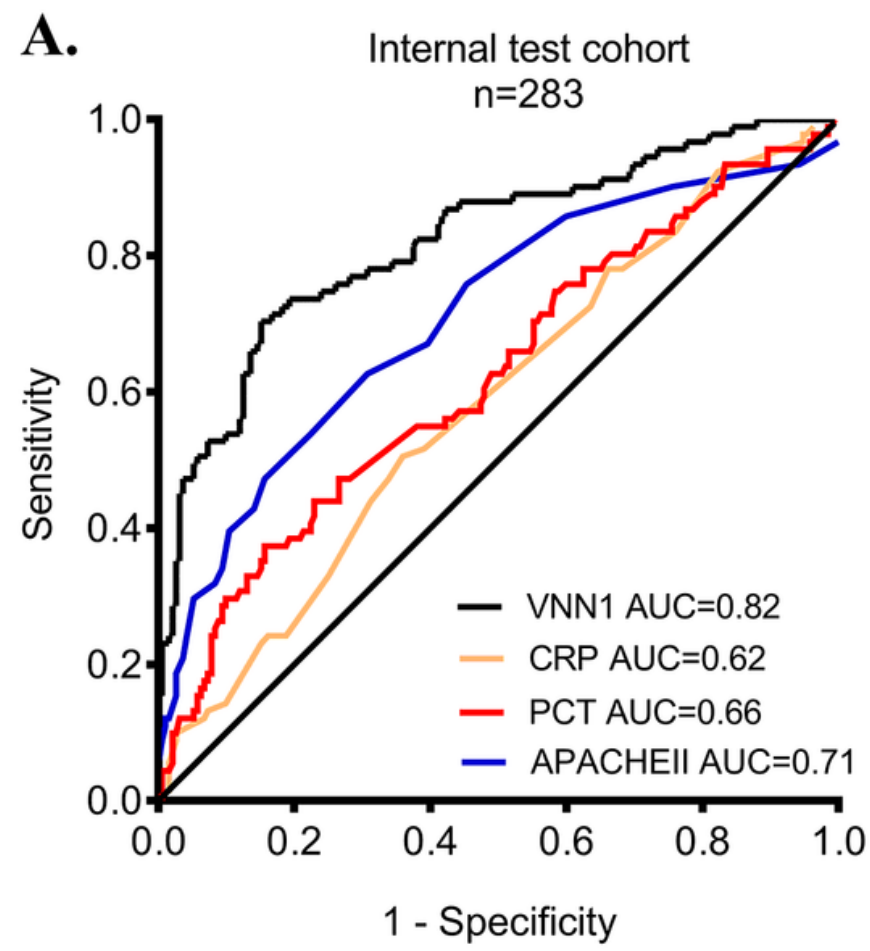

B. External validation cohort

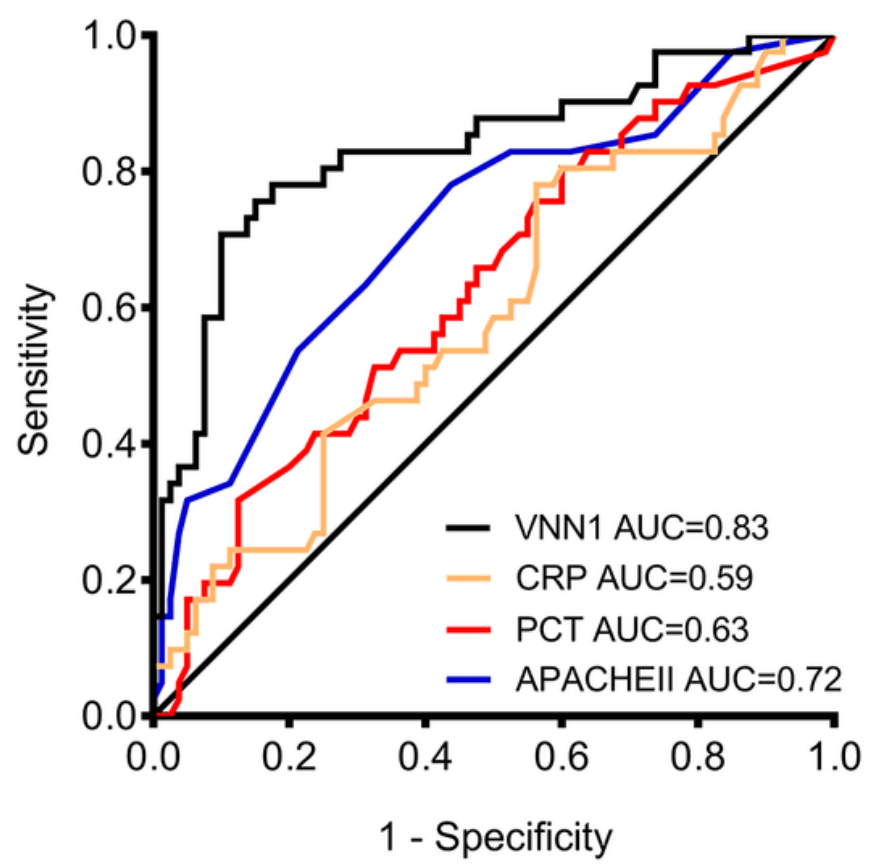

Figure 3

Receiver operating curve (ROC) analysis of VNN1, CRP, PCT, and APACHE II for sepsis after trauma. Plasma vanin-1 obtained the best predictive value compared to other biomarkers and scores in the internal test cohort $(A, n=283)$ and external validation cohort $(B, n=121)$.

\section{Supplementary Files}

This is a list of supplementary files associated with this preprint. Click to download.

- Additionalfile1.docx 